\title{
A Study on Correlation of Surgeon's Experience and Inadvertent Conjunctival Cyst Following SICS and Review of the Literature
}

\section{Venugopal Anitha ${ }^{1 *}$, Meenakshi Ravindran ${ }^{2}$, Mr Mohammed Sithiq Uduman $^{3}$ and Aditya Ghorpade ${ }^{4}$}

${ }^{1}$ Consultant in Cornea and Refractive Surgery, Aravind Eye Hospital, Tirunelveli, Tamilnadu, India

${ }^{2}$ Consultant Paediatric and Strabismus Surgery, Aravind Eye Hospital, Tirunelveli, Tamilnadu, India

${ }^{3}$ BioStatistician, Aravind Eye Hospital, Post Graduate Institute of Ophthalmology, Tirunelveli, Tamilnadu, India

${ }^{4}$ Consultant, Aravind Eye Hospital, Post Graduate Institute of Ophthalmology,

Tirunelveli, Tamilnadu, India

*Corresponding Author: Venugopal Anitha, Consultant in Cornea and Refractive Surgery, Aravind Eye Hospital, Tirunelveli, Tamilnadu, India.
Received: October 17, 2021

Published: November 18, 2021

(C) All rights are reserved by Venugopal

Anitha., et al.

\begin{abstract}
Purpose: To study the outcomes of patients with inadvertent conjunctival cyst following SICS procedure in correlation with surgeon's years of surgical experience, clinical, visual, and management effects with the review of literature in South Indian context.

Materials: A retrospective case record of patients presented with conjunctival cysts following SICS was evaluated. The data collection included demographic details, visual outcomes, slit-lamp findings, management outcomes, and complications, if any.

Results: The mean interval between the surgery date and the clinical presentation was 20.71months. The mean years of surgeon's experience were 6.01years. There was no significant relationship between the occurrence of the cyst and the surgeon's surgical experience.

Conclusion: Many novice surgeons are doing mSICS. Our observation will provide an insight into the rare complication of mSICS following poor wound construction and the steps to prevent the same during the learning process.
\end{abstract}

Keywords: Conjunctival Cyst; mSICS; Excision Biopsy; Surgeon Experience

\section{Introduction}

Conjunctival inclusion cysts are thin-walled sacs containing clear, serous, mucous, or mucopurulent fluid depending upon the aetiology [1]. It may appear following an infection [2], trauma, ocular surgery [2] and rarely following chronic usage of topical eye drops with preservatives [3]. It is known to be an immediate/late complication of manual small incision cataract surgery (SICS) [4], phacoemulsification [5], Strabismus surgery [6], pars plana vitrectomy [7], scleral buckling [8], Ahmed glaucoma valve surgery [9], or ptosis surgery [10].
MR Viswanath., et al. had reported inclusion cysts following sub tenon's anesthesia [11]. The incidence of conjunctival cyst following strabismus surgery is relatively high compared to other ocular surgeries [6]. The reported incidence of unintended cysts after cataract surgery is $1-7.7 \%$ [12]. It may occur due to sequestration of conjunctival epithelium in the scleral tunnel; poor wound healing response following surgery with aqueous leak into the subconjunctival space, poorly constructed scleral wounds, large incisions, excess cautery, and failure of the surgeon to identify the micro leaks intraoperatively [13]. It causes pain, foreign body sensation, and 
irritation $[2,5]$. There are many case reports of iatrogenic conjunctival cysts following mSICS which have existed in literature since 2010 [5]. Interestingly, we have reported fourteen patients with conjunctival cysts following manual SICS done by a varied group of cataract surgeons with different grades of surgical experience, from a tertiary eye care center and post-graduate training institute, South India, and discussed its management outcomes, preventive measures to be considered during surgery.

\section{Materials and Methods}

A retrospective review of datasheets of patients who presented with swelling under the upper lid following manual SICS surgery was included during the study period January 2017 to December 2019 (Figure 1 a, b and c). The demographic details, slit lamp findings of the patients such as the size of the cyst, time of presentation after surgery, and correlation of cyst occurrence concerning the surgeon's surgical experience in doing manual SICS, posterior segment examination, pre, and postoperative best-corrected visual acuity. The astigmatism changes in refraction pre and post-excision of the cyst were noted. Intraocular pressure (IOP) was measured using a non-contact tonometer (Keeler, USA) and confirmed with a tonopen (Reichert, New York) if needed. The size of the cyst was measured in the slit lamp, with both the arms of the microscope and slit lamp unit kept parallel, and the longest measurements in both horizontal and vertical directions were recorded. The surgeon's experience was noted in years after 100 numbers of initial SICS surgery. All patients were given anti-inflammatory eye drops for two weeks and monitored for spontaneous resolution of the cyst. After two weeks, the persistent or progressive cystic swellings were taken up for complete excision of the cyst.
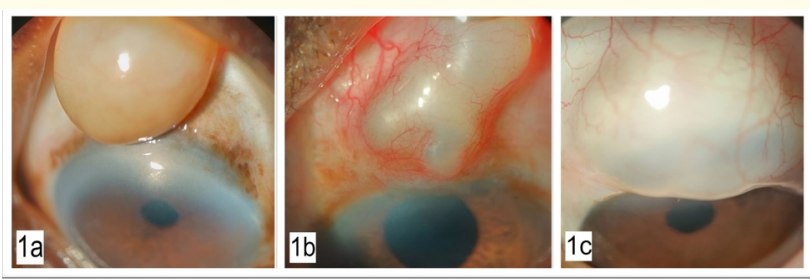

Figure 1 a, b and c: Preoperative images of the conjunctival cysts following mSICS procedures.

\section{Surgical procedure}

The surgical technique was done under peribulbar anesthesia with an operating microscope. The steps involved the usage of non-traumatic forceps and blunt tip scissors. The blunt tip scissors are used to separate the conjunctiva from the cyst wall and gently pulled with the non-traumatic forceps and separated with the scissors from the surrounding tissue. The conjunctiva above the cyst is used to hold the cyst firmly for further separation without rupturing the cyst. Care is taken when the base of the cyst is reached, the cyst is pulled away from the area of base dissection, and gently the cyst is removed in toto. The remnant conjunctiva was used to cover the bare sclera with or without scleral tunnel suturing depending upon its stability using glue or 10-0 vicryl sutures. The excised cyst was sent for histopathological examination. If the cyst ruptured, utmost care was taken to remove the wall and base of the cyst completely (Figure $1 \mathrm{~d}$ and e).
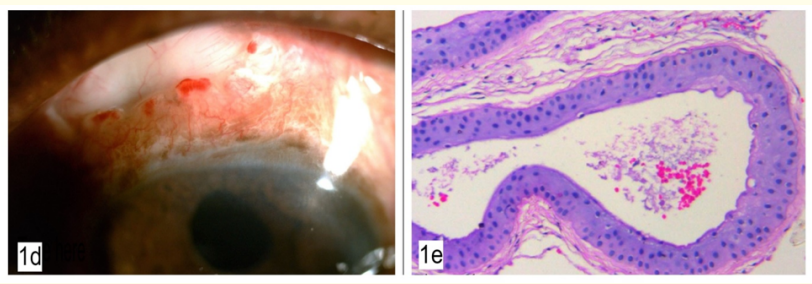

Figure $1 \mathbf{d}$ and e: Postoperative image following conjunctival cyst excision and histopathological image following cyst excision.

Post-operatively topical steroid antibiotic combination eye drops (Dexamethasone $0.1 \%$ + Gatifloxacin0.3\%) were prescribed in tapering dosage for four weeks, plain broad-spectrum antibiotics for one week. The patient was followed up in the first and fourth weeks. During every visit, slit-lamp examination, undilated fundus, and IOP were noted. This study complies with the "Declaration of Helsinki of the World Medical Association".

\section{Statistical methods}

Data were analyzed using the statistical software STATA version 14.0 (StataCorp, Texas, USA). Qualitative variables were presented as frequency ( $\mathrm{n}$ ) and percentage (\%), whereas quantitative data were represented by the mean and standard deviation (SD). Snellen's equivalent visual acuity was converted into a logarithm of minimal angle of resolution (log MAR) for statistical analysis. The normality of the data was examined using the Shapiro-Wilk test. Postoperative comparisons of visual acuity and astigmatism with the baseline were compared using a paired test. The correlation of the size of the cyst with the surgeon's experience and the presen- 
tation of the cyst were analyzed using Spearman rank correlation (rho). Also, the cyst size was compared between the surgeon experiences (years) using a one-way ANOVA statistical test. Any differences with a p-value less than 0.05 were considered as statistical significance.

\section{Results}

Our study included 14 eyes of 14 patients (seven males and seven females) with conjunctival cyst following cataract surgery during the study period from January 2017 to December 2019 (Table 1). All patients had a unilateral presentation (Figure 1). The Mean (SD) age of the patients was 64.7 years (7.6), ranging from 50-75 years. The mean follow-up was 6.5 months (2.8) following cyst excision. $64.3 \%$ of the patient's occupation was nil significant. No history of trauma was noted. Eleven patients (78.5\%) presented to us with complaints of swelling, two patients with ptosis (14.2\%), and one patient with sudden onset of Lagophthalmos (7.14\%). He was immediately taken up to the operating room for excision of the cyst to avoid exposure to keratopathy (Figure 2). The anterior chamber was well-formed with normal posterior segments in all the eyes. The mean IOP was $11.3 \mathrm{mmHg}$ (2.3). In all eyes, the cyst was found at 12 'oclock hours, beginning from the superior limbus; most of them were transparent, non-tender, non-compressible, and with well-defined margins. Only five eyes (35.7\%) required scleral tunnel suturing after cyst excision, probably poor wound healing or poor wound construction. In all the eyes, the cyst was excised by a single experienced surgeon (Figure $1 \mathrm{a}, \mathrm{b}$ and $\mathrm{c}$ ). In four eyes (28.5\%), the cyst ruptured during dissection. The histopathological examination revealed a cyst wall with non-keratinized stratified squamous epithelium with amorphous material (Figure $1 \mathrm{~d}$ and e). The mean (SD) size of the cyst was $5.68 \mathrm{~mm}$ (0.8). The mean (SD) interval between the surgery date and the first clinical presentation was 20.71 months (23.3). The mean years (SD) of surgeons' experience were 6.01(8.6) years. Spearman rank correlation was used to find out the significant relationship between the incidence of the cyst with the first presentation and the surgeon's experience. The p-value shows no significant relationship between the occurrence of the cyst and the surgeon's experience ( $r h o=0.41, \mathrm{p}+0.141)$ table 2. The mean (SD) baseline visual acuity was $1.35(0.6)$ in log MAR, and the mean postoperative visual acuity was $0.54(0.3)$, and the visual improvement is significant $(\mathrm{p}=0.0004)$. The mean baseline astigmatism was 0.84 (1.8), and post cyst excision was 1.06 (2.4) were not significant ( $p$-value of 0.285 ) (Table 1).

\begin{tabular}{|c|c|}
\hline Demographic details & Statistics \\
\hline Number of eyes & 14 \\
\hline $\begin{array}{l}\text { Laterality } \\
\text { Unilateral }\end{array}$ & 14 \\
\hline $\begin{array}{l}\text { Age, years } \\
\text { Mean (SD) }\end{array}$ & $64.07(7.6)$ \\
\hline Male gender, n (\%) & $7(50.0)$ \\
\hline $\begin{array}{l}\text { Follow-up, months } \\
\text { Mean (SD) }\end{array}$ & $6.5(2.8)$ \\
\hline $\begin{array}{l}\text { IOP, mmHg } \\
\text { Mean (SD) }\end{array}$ & $11.36(2.3)$ \\
\hline Simple cyst excision, n (\%) & $9(64.3)$ \\
\hline Cyst excision with tunnel sutures, n (\%) & $5(35.7)$ \\
\hline $\begin{array}{l}\text { Size of the cyst, mm } \\
\text { Mean (SD) }\end{array}$ & $5.68(0.8)$ \\
\hline $\begin{array}{l}\text { Interval between date of surgery and } \\
\text { clinical presentation, months } \\
\text { Mean (SD) }\end{array}$ & $20.71(23.3)$ \\
\hline $\begin{array}{l}\text { Surgeon experience, years } \\
\text { Mean (SD) }\end{array}$ & $6.01(8.6)$ \\
\hline $\begin{array}{l}\text { Visual acuity, logMAR } \\
\text { Baseline } \\
\text { Postoperative } \\
\text { P-value * }\end{array}$ & $\begin{array}{c}1.35(0.6) \\
0.54(0.3) \\
0.0004\end{array}$ \\
\hline $\begin{array}{l}\text { Astigmatism, D } \\
\text { Baseline } \\
\text { Postoperative } \\
\text { P-value * }\end{array}$ & $\begin{array}{c}-0.84(1.8) \\
-1.06(2.4) \\
0.285\end{array}$ \\
\hline
\end{tabular}

Table 1: Demographic and visual outcomes of patients with conjunctival cysts following mSICS procedure.

SD: Standard Deviation; * paired t-test; p-value $<0.05$ as significant.
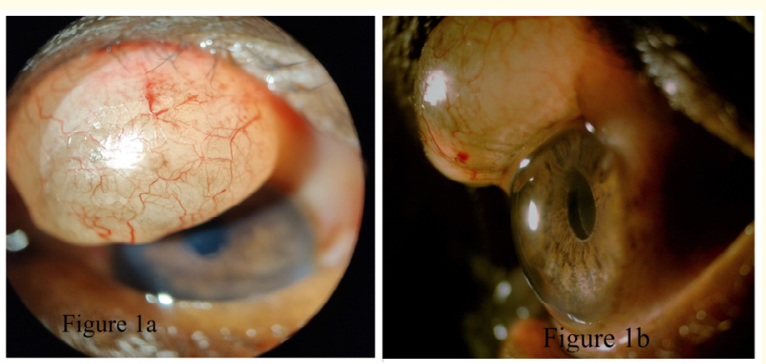

Figure 2: Images of patient showing large cyst with severe lagopthalmos. 


\begin{tabular}{|c|c|c|c|}
\hline $\begin{array}{l}\text { Surgeon experience, } \\
\text { years }\end{array}$ & $\mathbf{n}$ & Cyst size, mean(SD) & P-value \\
\hline$\leq 1$ & 6 & $5.42(1.0)$ & \multirow[t]{3}{*}{0.592} \\
\hline 1 to 5 & 4 & $6.00(0.9)$ & \\
\hline$>5$ & 4 & $5.75(0.6)$ & \\
\hline
\end{tabular}

Table 2: Comparison of cyst size with surgeon experience. ANOVA test.

\section{Discussion and Conclusion}

Conjunctival inclusion cysts comprise $6-13 \%$ of conjunctival lesions and $80 \%$ of the conjunctival cystic lesions [1]. Therefore, it can be classified as primary and secondary. The primary cysts are congenital, occurring spontaneously due to excessive invagination of caruncular epithelium or the fornix during embryonic development [2]. Secondary cysts arise following trauma, degeneration, parasitic infections, chronic inflammation such as vernal keratoconjunctivitis, Stevens-Johnson syndrome, ocular surgeries such as SICS, strabismus surgery, retinal surgeries $[13,14]$. The mSICS is a routine surgery that involves creating a scleral tunnel and removing cataracts in developing countries. Many case reports of conjunctival cysts following ocular surgeries exist in the literature [2-4]. Still, to the best of our knowledge, ours is a comprehensive study involving 14 patients concerning the surgeon's surgical experience and the occurrence of conjunctival cysts following the SICS procedure.
The first report of conjunctival cyst following SICS was done by S Narayanappa., et al. in 2010 [5]. Nath., et al. have evaluated the pathology, clinical features, and management of 45 patients with conjunctival cysts due to various causes [14]. Table 3 shows the comparison of our study details with the review of the literature. The proposed etiology of cysts in literature following ocular surgery includes implantation of conjunctival tissue in the tunnel wound, dragging the conjunctiva along with intraocular lens during its implantation, and the unstable scleral tunnel [2,5]. In our experience, the incidence of SICS cysts was not related to the surgeon's expertise; we have encountered cysts even with expert surgeons with more than six years of surgical experience. Hence the probable reason for SICS cyst could be unintended deep scleral dissection causing an unstable wound or excess cautery applied over the scleral vessels leading to delayed primary wound healing [1]. The deep scleral dissection may cause persistent wound leaks. Hence it is imperative to close the tunnel with sutures and form the anterior chamber watertight. Krishnacharya., et al. have proposed that minimum conjunctival tissue handling during IOL insertion would avoid the implantation of epithelium in the anterior chamber [2]. The careful conjunctival reflection before scleral wound construction and avoiding conjunctival contact with the IOL prevents inclusion cyst formation [2,5]. In literature, the unusual symptoms noted in patients with Conjunctival cyst include cosmetic discomfort, foreign body sensation, and ptosis [3].

\begin{tabular}{|c|c|c|c|c|c|c|}
\hline $\begin{array}{l}\text { Serial } \\
\text { number }\end{array}$ & $\begin{array}{c}\text { Authors and the year } \\
\text { of the study }\end{array}$ & Number of patients & $\begin{array}{l}\text { Predisposing factors for } \\
\text { Conjunctival cyst in the } \\
\text { study }\end{array}$ & Management & $\begin{array}{l}\text { Recurrences/ } \\
\text { Complications }\end{array}$ & Follow-up \\
\hline 2 & $\begin{array}{c}\text { Krishnacharya PS., et al. } \\
\text { [2] } 2013\end{array}$ & $\begin{array}{l}\text { Two } \\
\text { Two years } \\
\text { Eight years }\end{array}$ & $\begin{array}{c}\text { Extra capsular cataract } \\
\text { extraction }\end{array}$ & $\begin{array}{c}\text { Surgical excision } \\
\text { with Conjunctival } \\
\text { autograft was done }\end{array}$ & Nil Recurrence & Two years \\
\hline 3 & $\begin{array}{l}\text { Xiaoshan Min., et al. } \\
2017\end{array}$ & $\begin{array}{l}\text { Seven patients } \\
\text { Mean age: } 12.71 \\
\text { years }\end{array}$ & Strabismus surgery & Surgical excision & $\begin{array}{c}\text { One patient had } \\
\text { Methicillin resistant } \\
\text { Staphylococcus } \\
\text { aureus infection in } \\
\text { the cyst wall }\end{array}$ & NA \\
\hline 5 & $\begin{array}{c}\text { Shylaja Narayanapa., et } \\
\text { al. [5] } 2010\end{array}$ & $\begin{array}{l}\text { Two patients } \\
65 \text { years male } \\
67 \text { years male }\end{array}$ & SICS & $\begin{array}{l}\text { Surgical excision } \\
\text { with HPE }\end{array}$ & Nil recurrence & $\begin{array}{l}\text { Three } \\
\text { months }\end{array}$ \\
\hline
\end{tabular}

Citation: Venugopal Anitha., et al. "A Study on Correlation of Surgeon's Experience and Inadvertent Conjunctival Cyst Following SICS and Review of the Literature". Acta Scientific Ophthalmology 4.12 (2021): 47-52. 


\begin{tabular}{|c|c|c|c|c|c|c|}
\hline 6 & $\begin{array}{l}\text { Dong Hyun Kin., et al. } \\
2014\end{array}$ & $\begin{array}{l}\text { One patient } \\
66 \text { years old } \\
\text { Female }\end{array}$ & $\begin{array}{c}\text { Congenital atypical mass } \\
\text { extending from limbus to } \\
\text { medial canthus }\end{array}$ & \begin{tabular}{|c|} 
Enbloc excision \\
with HPE after CT \\
scan to rule out \\
orbital extension \\
\end{tabular} & NA & NA \\
\hline 7 & $\begin{array}{c}\text { Kavita Mallikarjun Sal- } \\
\text { agar., et al. [3] } 2015\end{array}$ & $\begin{array}{c}\text { One patient } \\
34 \text { years old male }\end{array}$ & $\begin{array}{c}\text { Topical anti- allergic } \\
\text { drops used for one year }\end{array}$ & Excision with HPE & Nil recurrence & One month \\
\hline 9 & $\begin{array}{l}\text { Shivraj Tagare., et al. } \\
2021\end{array}$ & $\begin{array}{l}\text { One patient } \\
67 \text { year old male }\end{array}$ & Scleral fixated iOL & $\begin{array}{l}\text { Surgical excision } \\
\text { and HPE }\end{array}$ & Nil recurrence & NA \\
\hline 10 & K Nath., et al. [14] & $\begin{array}{l}45 \text { patients with all } \\
\text { kinds of conjunctival } \\
\text { cystic lesions were } \\
\text { included }\end{array}$ & $\begin{array}{l}\text { Conjunctival epithelial } \\
\text { cysts, Dermoid, Parasitic } \\
\text { infections, Lymphatic } \\
\text { cysts, Oculo-dermal } \\
\text { melanocytois }\end{array}$ & $\begin{array}{l}\text { Surgical excision } \\
\text { and HPE }\end{array}$ & Nil recurrence & NA \\
\hline 11 & Our study & Fourteen patients & SICS & Excision with HPE & Nil recurrence & Six months \\
\hline
\end{tabular}

Table 3: Comparison of our study details with the Review of Literature.

Additionally, we have recognized lagophthalmos as the presenting complaint in one of our patients. The lagophthalmos was sudden in onset while washing his face. The most common differential diagnosis includes intentional filtering blebs done for control of IOP in glaucoma patients. The differentiating features include SICS cysts are thinner, larger with high internal illumination, and progressive compared to filtering bleb, which is either flat, vascular, if large, and cystic will be overhanging, but primarily stable associated with peripheral iridotomy. Both conditions can be differentiated with UBM or Gonioscopy, which reveals fish mouthing of the scleral tunnel in SICS cysts and sclerotomy with iridotomy in filtering bleb [16]. The management of conjunctival cyst depends on the symptoms. In asymptomatic individuals, cysts were conservatively managed [5]. Some authors have used thermal cautery [17], intracystic injection of ethanol [18], YAG laser [19], and ablation using atmospheric low-temperature Plasma [20] to the cyst as conservative measures. Patients with symptoms such as cosmetic disfigurement, progressive increase in the size of the cyst [20], foreign body sensation, and ptosis3 may need surgical intervention [21]. Al-Shehal., et al. recommended early surgical excision since the cyst would slowly enlarge in size and cause discomfort to the patient [22]. All our patients presented with swelling of the upper lid following the history of SICS except one. The complete excision of the cyst is the standard treatment for progressive conjunctival cysts; moreover, recurrence is troublesome in few patients. Our patients did not have any recurrence after surgical excision, with a mean follow-up of 6.5 months postoperatively.

The important differential diagnosis of conjunctival cysts is filtering blebs [2,16]. Gosalia NR., et al. have reported a case of inclusion cyst masquerading as an inadvertent bleb in a patient with Marfan's syndrome due to abnormal sclera [23]. Gonioscopy helps differentiate the etiology of the cyst, whether due to Trabeculectomy or the mSICS surgery, by viewing the fish mouthing of the scleral tunnel [13]. The complications include hypotonic maculopathy due to over filtration and endophthalmitis due to secondary infection [2], leading to vision loss. In all our patients, IOP was normal. The excision of the cyst was done immediately following the first clinical presentation, thus circumventing the complications and maintaining good visual acuity. Even now, SICS is the preferred surgical procedure for hard cataracts and corneas with low endothelial counts. Albeit an uneventful SICS procedure, the late postoperative complications of conjunctival cysts can occur, and the steps to prevent its appearance must be ensured intraoperatively. The avertible steps include adequate hydration of the side port, which normalizes the IOP and closes the roof and the floor of the tunnel, 
closure of the wound with sutures in case of accidental deep scleral dissection, minimum conjunctival dissection, minimal conjunctival manipulation during sub tenon's anesthesia, and avoiding excess scleral cautery.

Our study accentuates the importance of constructing a proper scleral tunnel and the preventive measures to avoid the formation of conjunctival cysts, a rare complication of ocular surgery. Therefore, the surgeons should become apprised of this condition and take necessary precautions to minimize the risk and achieve gratifying results.

\section{Competing Interests}

No financial interest in any of the product mentioned.

\section{Funding}

No funding received for the work.

\section{Bibliography}

1. Shields CL and Shields JA. "Tumors of the conjunctiva and cornea". Survey of Ophthalmology 49.14 (2004): 3-24.

2. Krishnacharya PS. “Tenon's Cyst Presenting as a Long-Term Complication following Incision Cataract Surgery". Case Reports in Medicine 2013 (2013): 759267.

3. Salagar K. "A Rare Case Report of Conjunctival Cyst". Journal of Clinical and Diagnostic Research 9.11 (2015): ND01-02.

4. Deshmukh S., et al. "Conjunctival inclusion cyst, an uncommon complication of a common surgery: a case report and review of the literature". Advances in Ophthalmology and Visual System 8.6 (2018): 298-299.

5. Narayanappa S., et al. "Conjunctival Inclusion cysts following small incision cataract surgery". Indian Journal of Ophthalmology 58.5 (2010): 423-425.

6. Song JJ., et al. "Giant secondary conjunctival inclusion Cysts: a late complication of strabismus surgery". Ophthalmology 113.6 (2006): 1049.

7. Bourcier T., et al. "Conjunctival Inclusion cyst following pars plana vitrectomy”. Archives of Ophthalmology 121.7 (2003): 1067.

8. Garg SP., et al. "Conjunctival cyst after retinal detachment surgery”. Indian Journal of Ophthalmology 36.4 (1988): 182-183.

9. Eibschitz-Tsimhoni M., et al. "Incidence and management of Encapsulated cysts following Ahmed glaucoma valve insertion". Journal of Glaucoma 14.4 (2005): 276-279.
10. Sameshima SS and Beyer-Machule CK. "Acquired ptosis associated with a conjunctival cyst". Ophthalmic Plastic and Reconstructive Surgery 4.3 (1988): 159-162.

11. Vishwanath MR and Jain A. "Conjunctival inclusion cyst following sub-Tenon's local anaesthetic Injection". British Journal of Anaesthesia 95.6 (2005): 825-826.

12. Swan KC and Campbell L. "Unintentional Filtration following Cataract Surgery". Archives of Ophthalmology 71.1 (1964): 4349.

13. Jain SS. "Inadvertent filtering bleb following sutureless cataract surgery". Indian Journal of Ophthalmology 53.3 (2005): 196-198.

14. Nath K., et al. "Cystic lesions of conjunctiva (a clinicopathogical study)". Indian Journal of Ophthalmology 31.1 (1983): 1-4.

15. Boynton JR., et al. "Primary nonkeratinized Epithelial ('conjunctival') orbital cysts". Archives of Ophthalmology 110.9 (1992): 1238-1242.

16. Tagare S and Christy JS. "Conjunctival Epithelial Inclusion Cyst". Delhi Journal of Ophthalmology 31.3 (2020): 93-94.

17. Hawkins AS and Hamming NA. "Thermal cautery as a treatment for conjunctival inclusion cyst after strabismus surgery". Journal of AAPOS 5.1 (2001): 48-49.

18. Simon JW. "Complications of strabismus surgery". Current Opinion in Ophthalmology 21.5 (2010): 361-366.

19. de Bustros $S$ and Michels RG. "Treatment of acquired epithelial inclusion cyst of the conjunctiva using the YAG laser". American Journal of Ophthalmology 98.6 (1984): 807-808.

20. Nejat F., et al. "A Novel Approach to Treatment of Conjunctival Cyst Ablation Using Atmospheric Low-Temperature Plasma". Clinical Ophthalmology 14 (2014): 2525-2532.

21. Thatte S and Gupta L. "Excision of post small incision cataract surgery conjunctival inclusion cyst". Indian Journal of Ophthalmology 59.3 (2011): 257-259.

22. Al-Shehah A and Khan AO. "Subconjunctival epithelial inclusion cyst complicating strabismus Surgery: Early excision is better". Saudi Journal of Ophthalmology 24.1 (2010): 27-30.

23. Gosalia NR., et al. "Cyst Masquerading as Inadvertent Bleb after a Scleral-Fixated Intraocular Lens in Marfan syndrome: A Case Report". Ophthalmology and Therapy 7.2 (2018): 437-441.

Volume 4 Issue 12 December 2021 (C) All rights are reserved by Venugopal Anitha., et al. 